\title{
A novel single nucleotide polymorphism within the NOD2 gene is associated with pulmonary tuberculosis in the Chinese Han, Uygur and Kazak populations
}

\author{
Mengyuan Zhao ${ }^{1}$, Feng Jiang ${ }^{2}$, Wanjiang Zhang ${ }^{3}$, Fujian $\mathrm{Li}^{4}$, Liliang Wei ${ }^{5}$, Jiyan Liu', Yun Xue ${ }^{1,6}$, Xiling Deng ${ }^{3}$, \\ Fang $\mathrm{Wu}^{3}$, Le Zhang ${ }^{3}$, Xing Zhang ${ }^{1}$, Yuxiang Zhang ${ }^{1}$, Dapeng Fan ${ }^{4}$, Xiaojun Sun ${ }^{5}$, Tingting Jiang ${ }^{1}$ and \\ Ji-Cheng $\mathrm{Li}^{1 *}$
}

\begin{abstract}
Background: The present study aimed to investigate the genetic polymorphisms in exon 4 of the NOD2 gene in tuberculosis patients and healthy controls, in order to clarify whether polymorphisms in the NOD2 gene is associated with tuberculosis.

Methods: A case-control study was performed on the Chinese Han, Uygur and Kazak populations. Exon 4 of the NOD2 gene was sequenced in 425 TB patients and 380 healthy controls to identify SNPs.

Results: The frequency of T/G genotypes for the Arg587Arg (CGT $\rightarrow$ CGG) single nucleotide polymorphism (SNP) in NOD2 was found to be significantly higher in the Uygur (34.9\%) and Kazak (37.1\%) populations than the Han population (18.6\%). Also, the frequency of $G / G$ genotypes for the Arg587Arg SNP was significantly higher in the Uyghur (8.3\%) and Kazak (5.4\%) populations than the Han population (0.9\%). Meanwhile, no significant difference was found in the Arg587Arg polymorphism between the tuberculosis patients and healthy controls in the Uyghur and Kazak populations ( $P>0.05$ ) whereas, a significant difference was observed in the Arg587Arg polymorphism between the tuberculosis patients and healthy controls in the Han population $(P<0.01)$. The odd ratio of 2.16 (95\% $\mathrm{Cl}=1.31-3.58 ; P<0.01)$ indicated that the Arg587Arg SNP in NOD2 may be associated with susceptibility to tuberculosis in the Chinese Han population.
\end{abstract}

Conclusions: Our study is the first to demonstrate that the Arg587Arg SNP in NOD2 is a new possible risk factor for tuberculosis in the Chinese Han population, but not in the Uyghur and Kazak populations. Our results may reflect racial differences in genetic susceptibility to tuberculosis.

Keywords: NOD2, Arg587Arg SNP, Tuberculosis, Chinese Han, Uyghur, Kazak

\section{Background}

According to the latest World Health Organization statistics, tuberculosis (TB) kills 1.7 million people each year, with 9.4 million new cases a year. It is estimated that $1 / 3$ of the world's population has been infected with mycobacterium TB. In the majority of infected people, the immune response is able to adequately control

\footnotetext{
* Correspondence: lijichen@zju.edu.cn

${ }^{1}$ Institute of Cell Biology, Zhejiang University, 866 Yuhangtang Road, Hangzhou 310058, China

Full list of author information is available at the end of the article
}

the infection, and consequently only $5-10 \%$ will develop clinically active TB disease during their lifetime [1]. The incidence of TB in different ethnic groups and countries is different. In $2009,55 \%$ of all TB cases occurred in Asia, 30\% in Africa, 7\% in Eastern Mediterranean Region, $4 \%$ in Europe and 3\% in the Americas [2].

China has the world's second largest TB epidemic. There is a significant difference in the incidence of TB in different regions, ethnic groups and populations [3]. The TB epidemic in the Western China is higher than the national average. The prevalence rate of active,

\section{Biomed Central}


sputum smear and culture positive TB in the Uygur, Kazak and Mongolian populations of the Xinjiang Uygur Autonomous Region (Northwest China) was found to be $12.4 \%, 16.9 \%$ and $18.4 \%$ higher than the Chinese Han population, respectively [4]. Therefore, the differences in susceptibility to TB may be related to a genetic predisposition. Several genes such as the natural resistanceassociated macrophage protein 1 [5], vitamin $\mathrm{D}$ receptor [6], toll-like receptor [7] and interleukin [8,9] have been associated with susceptibility to TB.

NOD2 (Nucleotide binding oligomerization domain containing 2) is a member of the nod-like receptor (NLR) family that acts as an intracellular pattern recognition receptor. Studies have shown that the NOD2 signaling pathway has a relatively independent recognition mechanism for mycobacterium TB [10]. NOD2 has been shown to recognize muramyl dipeptide (MDP), a component of bacterial cell wall peptidoglycan (PGN). Brooks et al. demonstrated that NOD2 controls the nature of the inflammatory response and subsequent fate of mycobacterium TB and mycobacterium bovis BCG in human macrophages [11]. Austin et al. sequenced exon 4 coding regions of the NOD2 gene in African Americans with TB disease and ethnically matched controlled subjects. They found that three common non-synonymous SNPs (single nucleotide polymorphisms), Pro268Ser, Arg702Trp, and Ala725Gly were significantly associated with TB disease. The Pro268Ser, Arg702Trp variations were protective against TB while, Ala725Gly polymorphism showed increased susceptibility to TB [12]. But, no association between exon 4 of the NOD2 gene and TB was found in the South African population [13]. Thus, polymorphisms of the NOD2 gene in TB may show great differences among different populations. Zhang et al. found that SNPs of NOD2 were associated with susceptibility to infection with mycobacterium Leprae [14]. In addition, 4 SNPs of the NOD2 have been identified to be associated with TB disease in the Chinese Han population, and one of the 4 SNPs showed a significant difference between the case and the control groups [15].

We investigated the Arg587Arg polymorphism within the exon 4 of NOD2 in the Chinese Han, Uygur and Kazak populations associated with TB, which was located in the winged helix and superhelical domain of NOD2 [16]. The difference between frequencies of NOD2 polymorphisms revealed susceptibility to TB in these populations and provides the experimental basis for TB risk assessment.

\section{Methods}

\section{Patients and control subjects}

The patients and healthy control subjects enrolled in the study were as follows: For the Han population, 219 TB patients aged 18-65 years (mean age $36.47 \pm 15.73$ years) from the Sixth Hospital of Shaoxing, Taizhou Shiwei Hospital and Hangzhou Red Cross Hospital, and 215 healthy controls aged 20-60 years (mean age $37.02 \pm$ 15.29 years); for the Uygur population $86 \mathrm{~TB}$ patients aged 20-70 years (mean age $28.8 \pm 10.1$ years) from the Second People's Hospital of Aksu, Xinjiang and Wensu County People's Hospital, and 72 healthy controls aged 20 -60 years (mean age $30.1 \pm 8.9$ years); for the Kazak population, $120 \mathrm{~TB}$ patients aged $20-70$ years (mean age $28.8 \pm 10.1$ years) from the Tacheng District Hospital, Xinjiang, and 93 healthy controls, aged 20-60 years (mean age $37.02 \pm 15.29$ years), Table 1.

Table 1 Characteristics of healthy controls and TB patients in the Han, Uygur and Kazak populations

\begin{tabular}{|c|c|c|c|c|}
\hline & & $\begin{array}{c}\text { Age } \\
(\text { mean } \pm \text { SD) }\end{array}$ & $\begin{array}{c}\text { Sex } \\
\text { (female: } \text { male) }\end{array}$ & Pulmonary $\mathrm{TB}$ \\
\hline \multirow[t]{3}{*}{ Han } & $\begin{array}{c}\text { TB group } \\
\mathrm{n}=219\end{array}$ & $\begin{array}{c}18-65 \\
(36.47 \pm 15.73)\end{array}$ & $85: 134$ & 219 \\
\hline & $\begin{array}{c}\text { Control group } \\
n=215\end{array}$ & $\begin{array}{c}20-60 \\
(37.02 \pm 15.29)\end{array}$ & $88: 127$ & ND \\
\hline & P & $0.541^{\mathrm{a}}$ & $0.643^{b}$ & \\
\hline \multirow[t]{3}{*}{ Uygur } & $\begin{array}{l}\text { TB group } \\
n=86\end{array}$ & $\begin{array}{c}20-70 \\
(28.8 \pm 10.1)\end{array}$ & $37: 49$ & 86 \\
\hline & $\begin{array}{c}\text { Control group } \\
n=72\end{array}$ & $\begin{array}{c}20-60 \\
(30.1 \pm 8.9)\end{array}$ & $31: 41$ & ND \\
\hline & P & $0.495^{\mathrm{a}}$ & $0.569^{b}$ & \\
\hline \multirow[t]{3}{*}{ Kazak } & $\begin{array}{c}\text { TB group } \\
\mathrm{n}=120\end{array}$ & $\begin{array}{c}20-70 \\
(28.8 \pm 10.1)\end{array}$ & $66: 54$ & 120 \\
\hline & $\begin{array}{c}\text { Control group } \\
n=93\end{array}$ & $\begin{array}{c}20-60 \\
(37.02 \pm 15.29)\end{array}$ & $53: 40$ & ND \\
\hline & P & $0.642^{\mathrm{a}}$ & $0.536^{b}$ & \\
\hline
\end{tabular}

$\mathrm{TB}=$ tuberculosis; ND = not determined

a $P$ value between total patients and controls, for $T$-test

${ }^{\mathrm{b}} P$ value between total patients and controls, for $\chi^{2}$ test 
The patients were diagnosed as having pulmonary TB based on results from acid-fast staining of sputum smear, positive tuberculin skin test and chest X-ray examination. The patients and controls were HIV negative and none was known to present any autoimmune, chronic inflammatory or any other disease conditions. All selected participants had no mixed descendants within three generations. The study was approved by the Ethics Committee of the Faculty of Medicine (Zhejiang University, China), and informed consents were obtained from all subjects before blood sampling.

\section{Genomic DNA extraction from blood}

Genomic DNAs were extracted from the TB patients and healthy controls with the salting-out method. The frozen whole blood with anticoagulant was thawed in a $37^{\circ} \mathrm{C}$ water bath and 4 volumes of red blood cell lysis buffer were added for lysing red blood cells. Then, $100 \mu \mathrm{l}$ of white lysis buffer was added for lysing white blood cells. After incubation with proteinase $\mathrm{K}$ at $56^{\circ} \mathrm{C}$, the purified DNA was collected by ethanol precipitation. Finally, gel electrophoresis and UV spectrophotometer were used to determine the DNA concentration and purity. The sample DNA was diluted with TE buffer to make a final concentration of $100 \mu \mathrm{g} / \mathrm{ml}$ working solution.

\section{PCR amplification}

Primers for exon 4 of the NOD2 gene were designed using the prime 5.0, which included, F1: CAGACTCAGCTTCCCAAGG; R1: AGGTGCCCAACATTCAGG (Gene ID: 64127). PCR amplification was performed using purified DNA in a $50 \mu \mathrm{l}$ reaction at $93^{\circ} \mathrm{C}$ for $3 \mathrm{~min}$, $95^{\circ} \mathrm{C}$ for $50 \mathrm{~s}, 58^{\circ} \mathrm{C}$ for $3 \mathrm{~s}$, followed by 30 cycles at $72^{\circ} \mathrm{C}$ for $50 \mathrm{~s}$ and a final extension at $94^{\circ} \mathrm{C}$ for $5 \mathrm{~min}$. The PCR products were sequenced using BigDye Terminator v3.1 Cycle Sequencing Kit (Applied Biosystems, Foster City, USA) and analyzed on an ABI 3730XL (Applied Biosystems, Foster City, USA) sequencer.

\section{Statistical analysis}

The Mutation Explorer/Mutation Surveyor Version 2.2 was used for polymorphisms analysis. The comparison of age and gender between patients and controls in different populations was assessed using chi-square test and $T$-test performed with SPSS for windows (version 16.0). The genotype frequencies were assessed for Hardy-Weinberg equilibrium. The difference in allele frequencies between patients and the control groups was tested by $\chi^{2}$, and the genotype frequencies were analysed by Armitage Trend test and $\chi^{2}$ [17]. $P$ value $<$ 0.05 was considered statistically significant.

\section{Results}

The exon 4 of the NOD2 gene was sequenced in $425 \mathrm{~TB}$ patients and 380 healthy controls to identify SNPs, in the Chinese Han, Uygur and Kazak populations (Figure 1). A total of 18 SNPs were found in the TB patients and the healthy controls. Except Arg587Arg SNP, the frequencies of other 17 polymorphisms were inferred lower than $1 \%$, and we pooled all the rare variants and compared the frequencies (Table 2). The frequencies of rare variants in NOD2 showed no significant differences between the cases and controls $(\mathrm{OR}=2.220,95 \% \mathrm{CI}=0.911-5.414$, $P=0.072$ ). The frequencies of Arg587Arg SNPs in the Chinese Han, Uygur and Kazak patients with TB were $25 \%, 43 \%$ and $45.8 \%$, respectively, whereas, the frequencies in the Chinese Han, Uygur and Kazak healthy controls were $14 \%, 48.6 \%$ and $39.8 \%$, respectively (Table 3 ).

The G allele frequencies of Arg587Arg SNP in the Chinese Han, Uygur and Kazak patients with TB were $14 \%, 26 \%, 26 \%$, respectively, whereas, the G allele frequencies in the Chinese Han, Uygur and Kazak healthy controls were $7 \%, 28 \%, 23 \%$, respectively (Table 4 ).

The data showed that in the Han population, the G allele frequency of the Arg587Arg SNP in the patient group was twice as high than in the control group, indicating a significant difference between the two groups $(P=0.002)$. But, in the Uygur and Kazak populations, no significant difference in the $G$ allele frequencies was observed between the patients and the controls $(P=$ 0.646 and 0.382 , respectively).

By comparing the TG genotype frequencies of Arg587Arg SNP in the Han population, a significant difference was observed between the patients with $\mathrm{TB}$ and the healthy controls $(P=0.0023$; OR $=2.16 ; 95 \% \mathrm{CI}=$ 1.31-3.58). No significant difference in the TG genotype frequencies of Arg587Arg SNP in the Uygur and Kazak populations was observed between the patients and the healthy controls $(P=0.6575$ and 0.3838 , respectively). These results indicated that the Arg587Arg SNP are associated with susceptibility to TB and may be a risk factor for the development of TB in the Chinese Han population.

\section{Discussion}

Mycobacterium TB is a typical intracellular parasite. Once inside the alveoli, the MDP of the bacterial cell wall stimulate pattern recognition receptors (PRRs). The PRRs include NOD-like receptors, toll-like receptors and mannose receptors [15]. NOD2, a member of the NLR family, encodes a protein with caspase activation recruitment domains (CARDs) and leucine-rich repeats (LRRs). CARD interacts with receptor-interacting protein 2 (RIP2), triggering a series of downstream signal transduction pathways. This leads to the activation and 


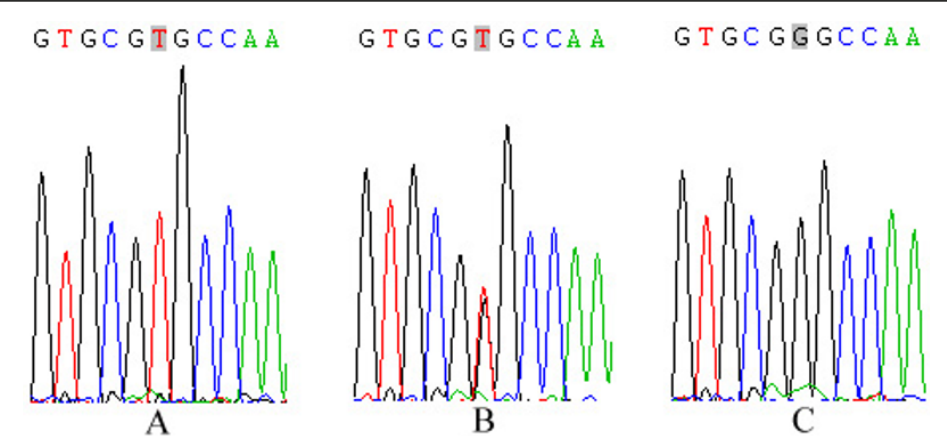

Figure 1 DNA sequences of Arg587Arg in exon 4 of the NOD2. A: the genotype of T/T; B: the genotype of T/G; C: the genotype of G/G.

translocation of nuclear factor kappa $\mathrm{B}(\mathrm{NF} \kappa \mathrm{B})$ into the nucleus, where it stimulates the transcription and expression of inflammatory cytokines [18-20].

It has been reported that binding of NOD2 and PGN breakdown products of mycobacterium TB can exert certain synergistic effects on tumor necrosis factor and the NOD2 signaling pathway has a relatively independent recognition mechanism for mycobacterium. In addition, NOD2 polymorphisms have been associated with susceptibility to Crohn's disease [21], inflammatory bowel disease [22], pulmonary sarcoidosis [23] and several other diseases.

Our study was the first to investigate the SNPs in exon 4 of the NOD2 gene among the Chinese Han, Uygur and Kazak patients with TB. We found 18 mutations and of these, the frequencies of 17 mutations were less than 1\%. Only the Arg587Arg frequencies were high

Table 2 Rare nonsynonymous and synonymous variation of NOD2 gene in the cases and control

\begin{tabular}{|c|c|c|c|c|}
\hline $\begin{array}{l}\text { Amino acid } \\
\text { variation } \\
\text { (codon variation) }\end{array}$ & $\begin{array}{l}\text { Case } \\
\text { patients } \\
\mathrm{n}=425\end{array}$ & $\begin{array}{l}\text { Control } \\
\text { subjects } \\
\mathrm{n}=380\end{array}$ & $\begin{array}{l}\text { OR } \\
(95 \% \mathrm{Cl})\end{array}$ & $P$-value \\
\hline Arg541Trp(CGG-TGG) & 2 & 2 & & \\
\hline Ala579Gly(GCC-GGC) & 3 & 0 & & \\
\hline Phe584Phe(TTC-TTT) & 2 & 0 & & \\
\hline Ala588Ala(GCG-GCA) & 0 & 1 & & \\
\hline Ala611Ala(GCC-GCT) & 5 & 0 & & \\
\hline Ala612Thr(GCG-ACG) & 1 & 0 & & \\
\hline Ala661Pro(GCT-CCT) & 1 & 2 & & \\
\hline Glu667Lys(GAG-AAG) & 0 & 1 & & \\
\hline Pro668Pro(CCG-CCT) & 1 & 0 & & \\
\hline Arg708His(CGC-CAC) & 1 & 0 & & \\
\hline Aal725Val(GCT-GTT) & 0 & 1 & & \\
\hline Pro727Pro(CCG-CCA) & 1 & 0 & & \\
\hline Total & 17 & 7 & $\begin{array}{l}2.220 \\
(0.911-5.414)\end{array}$ & 0.072 \\
\hline
\end{tabular}

The total occurrences of rare nonsynonymous and synonymous polymorphisms were compared between case patients and control subjects by use of a $\chi^{2}$ test for 2-by-2 contingency tables.

$\mathrm{Cl}$, confidence interval; $\mathrm{OR}$, odds ratio. in the Chinese Han, Uygur and Kazak populations, and particularly higher in the Uygur and Kazak populations with TB.

Our study found that the frequencies of Arg587Arg SNP in healthy controls and TB patients were much higher in minority populations than the Han population. The frequency of $\mathrm{G}$ allele was also higher in minority populations than the Han population. These results indicated that there was a significant difference in Arg587Arg SNP among different ethnic groups.

Arg587Arg is located on the winged helix and superhelical domain of the NOD2 protein and linked to the NACHT domain [16] for synonymous mutations. In the Han population, the frequency of Arg587Arg G/T genotype was twice as high in the patient group than in the control group, indicating that the G/T genotype frequency is associated with an increased risk of TB. There was significant difference between TB patients and healthy controls. But, no significant difference of the G/T genotype frequency was observed between the TB patients and healthy controls in the Uygur and Kazak populations.

Sato et al. studied NOD2 polymorphisms associated with pulmonary sarcoidosis [23] and found that Arg587Arg G allele was associated with significantly better lung function parameters than the wild-type allele. In Crohn's disease, the frequency of Arg587Arg G allele was found to be much higher in the control group compared to the disease group [24]. Zhang et al. performed genome-wide association study of leprosy and identified four SNPs in NOD2 (rs9302752, rs7194886, rs8057341, and rs3135499) as leprosy risk factors [14]. In the present study, we found that the Arg587Arg polymorphism (CGG $\rightarrow$ TGG) have a relatively high risk for TB in the Chinese Han population $(\mathrm{OR}=2.16,95 \% \mathrm{CI}=1.31-3.58$, $P=0.0023)$. In the African American population, three common non-synonymous SNPs in the NOD2 gene such as, Arg702Trp (CGG $\rightarrow$ TGG), Pro268Ser (CCC $\rightarrow$ TCC) and Ala725Gly (GCT $\rightarrow$ GGT) have been demonstrated to be associated with TB disease [12]. However, in the South African [13] and Gambian populations [25], 
Table 3 The genotype frequencies of Arg587Arg (CGT $\rightarrow$ CGG) SNP of NOD2 gene in patients and controls of Chinese Han, Uyghur and Kazak populations

\begin{tabular}{|c|c|c|c|c|c|}
\hline & Genotype & Patients & Controls & Trend P-value & $\begin{array}{c}\text { OR } \\
(95 \% \mathrm{Cl})\end{array}$ \\
\hline & & $\mathrm{N}$ (Freq) & $N$ (Freq) & & \\
\hline \multirow[t]{3}{*}{ Han } & $\mathrm{T} / \mathrm{T}$ & $162(0.74)$ & 185(0.86) & & 1.00 \\
\hline & $\mathrm{T} / \mathrm{G}$ & $53(0.242)$ & 28(0.13) & 0.0023 & $2.16(1.31-3.58)$ \\
\hline & $\mathrm{G} / \mathrm{G}$ & $4(0.018)$ & $2(0.009)$ & & $2.28(0.41-12.63)$ \\
\hline \multirow[t]{3}{*}{ Uygur } & $\mathrm{T} / \mathrm{T}$ & $49(0.57)$ & $37(0.514)$ & & 1.00 \\
\hline & $T / G$ & $29(0.337)$ & $29(0.403)$ & 0.6575 & $0.76(0.39-1.47)$ \\
\hline & $\mathrm{G} / \mathrm{G}$ & $8(0.093)$ & $6(0.083)$ & & $1.01(0.32-3.15)$ \\
\hline \multirow[t]{3}{*}{ Kazak } & $\mathrm{T} / \mathrm{T}$ & $65(0.542)$ & $56(0.602)$ & & 1.00 \\
\hline & $T / G$ & $47(0.392)$ & $32(0.344)$ & 0.3838 & $1.27(0.71-2.25)$ \\
\hline & $\mathrm{G} / \mathrm{G}$ & $8(0.067)$ & 5(0.054) & & $1.38(0.43-4.46)$ \\
\hline
\end{tabular}

Genotype frequencies were compared between the patients and control subjects by Armitage Trend test and $\chi^{2}$ test. $\mathrm{N}=$ number of alleles; Freq $=$ frequency; $\mathrm{Cl}$ = confidence interval; $\mathrm{OR}=$ odds ratio.

Table 4 The allele frequency of Arg587Arg (CGT $\rightarrow$ CGG) SNP of NOD2 gene in the patients and controls of Chinese Han, Uygur and Kazak populations

\begin{tabular}{|c|c|c|c|c|c|}
\hline & & \multicolumn{2}{|c|}{ Allele frequency } & \multirow[t]{2}{*}{ P-value } & \multirow{2}{*}{$\begin{array}{c}\text { OR } \\
(95 \% \mathrm{Cl})\end{array}$} \\
\hline & & Patients, N(Freq) & Controls, N(Freq) & & \\
\hline \multirow[t]{2}{*}{ Han } & $\mathrm{T}$ & $377(0.86)$ & 398(0.93) & 0.002 & $\begin{array}{c}2.012 \\
(1.283-3.157)\end{array}$ \\
\hline & G & $61(0.14)$ & $32(0.07)$ & & \\
\hline HWE(P) & & & 0.32 & & \\
\hline \multirow[t]{2}{*}{ Uygur } & $\mathrm{T}$ & $127(0.74)$ & $103(0.72)$ & 0.646 & $\begin{array}{c}0.890 \\
(0.498-1.401)\end{array}$ \\
\hline & G & $45(0.26)$ & $41(0.28)$ & & \\
\hline HWE(P) & & & 1 & & \\
\hline \multirow[t]{2}{*}{ Kazak } & $\mathrm{T}$ & $177(0.74)$ & $144(0.77)$ & 0.382 & $\begin{array}{c}1.220 \\
(0.780-1.910)\end{array}$ \\
\hline & G & $63(0.26)$ & $42(0.23)$ & & \\
\hline HWE(P) & & & 1 & & \\
\hline
\end{tabular}

Allele frequencies were compared between the patients and control subjects by use of a $\chi^{2}$ test for 2-by-2 contingency tables. HWE $=\mathrm{Hardy}$-Weinberg equilibrium; $\mathrm{N}=$ number of alleles; Freq = frequency; $\mathrm{Cl}=$ confidence interval; $\mathrm{OR}=$ odds ratio.

no significant associations were observed between the NOD2 polymorphisms and TB disease.

Our study found that in the healthy controls, the frequency of $\mathrm{T} / \mathrm{G}$ genotype in the Uygur and Kazak populations was twice as the Han population. Among Han population, the frequency of $\mathrm{T} / \mathrm{G}$ genotype in the patients was twice as that of the control group. There was no significant difference in the genotype frequencies between the patients and the control groups in the Uygur and Kazak populations. However, T/G genotype was found significantly susceptible to TB in the Han population. Based on the above analysis, we believed that Arg587Arg SNP is associated with TB and is closely related to the genetic nature of the population.

The present study is the first to report that there is no significant association between Arg587Arg SNP of the NOD2 and TB in the Uygur and Kazak populations. But, Arg587Arg is significantly associated with the TB patients and healthy controls in the Han population and is a risk factor for TB disease in Chinese Han. The findings of this study provide data for the assessment of risk profiles regarding susceptibility to $\mathrm{TB}$ and also provide a molecular basis for the detection of functional changes resulting from synonymous mutations.

\section{Conclusions}

Arg587Arg SNP in NOD2 is associated with susceptibility to $\mathrm{TB}$ and may be a risk factor for the development of TB in the Chinese Han population, but it did not show significant difference between the controls and cases neither in the Uyghur population or Kazak populations.

\section{Abbreviations}

TB: Tuberculosis; NOD2: Nucleotide-binding oligomerization domain containing2; SNP: Single nucleotide polymorphism; NLR: Nod-like receptor; 
PGN: Peptidoglycan; PRRs: Pattern recognition receptors; CARDs: Recruitment domains; LRRs: Leucine-rich repeats; RIP2: Receptor-interacting protein 2; NFkB: Nuclear factor kappa B.

\section{Acknowledgements}

This work was supported by grants from Zhejiang Province Special Sci-Tech Projects (No.2009 C03011-3), National Natural Science Foundation of China (No.81072724), and National Special Sci-Tech Projects (No.2012ZX10005001006; No.2008ZX10005-010)

\section{Author details}

${ }^{1}$ Institute of Cell Biology, Zhejiang University, 866 Yuhangtang Road, Hangzhou 310058, China. 'Dongzhimen Hospital Affiliated to Beijing University of Chinese Medicine, Beijing 100700, China. ${ }^{3}$ Department of Pathophysiology, Shihezi University School of Medicine, Xinjiang 832003, China. ${ }^{4}$ The Fifth Hospital of Hangzhou, Hangzhou 310003, China. ${ }^{5}$ The Sixth Hospital of Shaoxing, Shaoxing 312000, China. ${ }^{6}$ Henan University of Science and Technology, Luoyang 471003, China.

\section{Authors' contributions}

$J C \mathrm{Li}$ is responsible for the experiment and paper. MY Zhao, F Jiang, JY Liu, $Y$ Xue participated in the sample collecting and analysis of data. WJ Zhang, XL Ddeng, F Wu, L Zhang, FJ Li, LL Wei, DP Fan and XJ Sun enrolled the blood of controls and patients. X Zhang, XY Zhang and TT Jiang participated in data analysis. All authors read and approved the final manuscript.

\section{Competing interests}

The authors declare that they have no competing interests.

Received: 14 November 2011 Accepted: 14 April 2012 Published: 14 April 2012

\section{References}

1. Toth A, Fackelmann J, Pigott W, Tolomeo O: Tuberculosis prevention and treatment. Can Nurse 2004, 100:27-30.

2. World Health Organization: Global tuberculosis control: a short update to the 2009 report., Available at: http://whqlibdoc.who.int/publications/2009/ 9789241598866_eng.pdf. Accessed: 8 January 2011.

3. National Technic Steering Group of the Epidemiolocal Sampling Survey for Tuberculosis: Report on fourth national epidemiological sampling survey of tuberculosis. Chin Tuberc Respir Dis 2002, 2:3-7.

4. Xin J, Xinchun F, Huakui Y: Report in the fourth epidemiological survey for tuberculosis in Xinjiang Uygur Autonomous Region. Chin J Antituberculosis 2004, 26:264-267.

5. Nugraha J, Anggraini R: NRAMP1 polymorphism and susceptibility to lung tuberculosis in Surabaya, Indonesia. Southeast Asian J Trop Med Public Health 2011, 42:338-341.

6. Bornman L, Campbell SJ, Fielding K, Bah B, Sillah J, Gustafson P, Manneh K, Lisse I, Allen A, Sirugo G, Sylla A, Aaby P, McAdam KP, Bah-Sow O, Bennett S, Lienhardt C, Hill AV: Vitamin D receptor polymorphisms and susceptibility to tuberculosis in West Africa: a case-control and family study. J Infect Dis 2004, 190:1631-1641.

7. Xue Y, Jin L, Li AZ, Wang HJ, Li M, Zhang YX, Wang Y, Li JC: Microsatellite polymorphisms in intron 2 of the toll-like receptor 2 gene and their association with susceptibility to pulmonary tuberculosis in Han Chinese. Clin Chem Lab Med 2010, 48:785-789.

8. Shin HD, Park BL, Kim YH, Cheong HS, Lee IH, Park SK: Common interleukin 10 polymorphism associated with decreased risk of tuberculosis. Exp Mol Med 2005, 37:128-132.

9. Ben-Selma W, Ben-Abderrahmen Y, Boukadida J, Harizi H: IL-10R1 S138G loss-of-function polymorphism is associated with extrapulmonary tuberculosis risk development in Tunisia. Mol Biol Rep 2011.

10. Ferwerda G, Girardin SE, Kullberg BJ, Le Bourhis L, de Jong DJ, Langenberg DM, Van Crevel R, Adema GJ, Ottenhoff TH, Van der Meer JW Netea MG: NOD2 and toll-like receptors are nonredundant recognition systems of Mycobacterium tuberculosis. PLoS Pathog 2005, 1:279-285.

11. Brooks MN, Rajaram MV, Azad AK, Amer AO, Valdivia-Arenas MA, Park JH, Núñez G, Schlesinger LS: NOD2 controls the nature of the inflammatory response and subsequent fate of Mycobacterium tuberculosis and $\mathrm{M}$. bovis BCG in human macrophages. Cell Microbiol 2011, 13:402-418.
12. Austin $C M, M a X$, Graviss EA: Common Nonsynonymous Polymorphisms in the NOD2 Gene are Associated with Resistance or Susceptibility to Tuberculosis Disease in African Americans. J Infect Dis 2008, 197:1713-1716.

13. Möller M, Nebel A, Kwiatkowski R, van Helden PD, Hoal EG, Schreiber S: Host susceptibility to tuberculosis:CARD15 polymorphisms in a South African population. Mol Cell Probes 2007, 21:148-151.

14. Zhang FR, Huang W, Chen SM, Sun LD, Liu H, Li Y, Cui Y, Yan XX, Yang HT, Yang RD, Chu TS, Zhang C, Zhang L, Han JW, Yu GQ, Quan C, Yu YX, Zhang Z, Shi BQ, Zhang LH, Cheng H, Wang CY, Lin Y, Zheng HF, Fu XA, Zuo XB, Wang Q, Long H, Sun YP, Cheng YL, Tian HQ, Zhou FS, Liu HX, Lu WS, He SM, Du WL, Shen M, Jin QY, Wang Y, Low HQ, Erwin T, Yang NH, $L i$ JY, Zhao X, Jiao YL, Mao LG, Yin G, Jiang ZX, Wang XD, Yu JP, Hu ZH, Gong CH, Liu YQ, Liu RY, Wang DM, Wei D, Liu JX, Cao WK, Cao HZ, Li YP, Yan WG, Wei SY, Wang KJ, Hibberd ML, Yang S, Zhang XJ, Liu JJ: Genomewide association study of leprosy. N Engl J Med 2009, 361:2609-2618.

15. Pan H, Dai Y, Tang S, Wang J: Polymorphisms of NOD2 and the risk of tuberculosis: a validation study in the Chinese population. Int $J$ Immunogenet 2012, doi:10.1111/j.1744-313X.2011.01079.x.

16. Proell M, Riedl SJ, Fritz JH, Rojas AM, Schwarzenbacher R: The Nod-Like Receptor (NLR) Family: a tale of similarities and differences. PLOS ONE 2008, 3:e2119.

17. Velez DR, Hulme WF, Myers JL, Brice-Weinberg J, Levesque MC, Stryjewski ME, Abbate E, Estevan R, Patillo SG, Gilbert JR, Hamilton CD, Scott WK: NOS2A, TLR4, and IFNGR1 interactions influence pulmonarytuberculosis susceptibility in African-Americans. Hum Genet 2009, 126:643-653,

18. Inohara N, Nuñez G: NODS: intracellula proteins involved in inflammation and apoptosis. Nature Rev Immunol 2003, 3:371-382.

19. Inohara N, Koseki T, del Peso L, Hu Y, Yee C, Chen S, Carrio R, Merino J, Liu D, Ni J, Núñez G: Nod1, an Apaf--like activator of casepase-9 and nuclear-factor-KB. J Biol Chem 1999, 274:14560-14567.

20. Ogura Y, Inohara N, Benito A, Chen FF, Yamaoka S, Núñez G: Nod2, a Nod/ Apaf-I family menber that is restricted to monocytes and activates NFKB. J Biol Chem 2001, 276:4812-4818.

21. Gasche C, Nemeth M, Grundtner P, Willheim-Polli C, Ferenci P, Schwarzenbacher R: Evolution of Crohn's disease-associated Nod2 mutations. Immunogenetics 2008, 60:115-120.

22. Cho JH, Abraham C: Inflammatory bowel disease genetics: Nod2. Annu Rev Med 2007, 58:401-416.

23. Sato H, Williams HR, Spagnolo P, Abdallah A, Ahmad T, Orchard TR, Copley SJ, Desai SR, Wells AU, du Bois RM, Welsh KI: CARD15/NOD2 polymorphisms are associated with severe pulmonary sarcoidosis. Eur Respir J 2010, 35:324-330.

24. Lesage S, Zouali H, Cezard JP, Belaiche J, Almer S, Tysk C, O'Morain C, Gassull M, Binder V, Finkel Y, Modigliani R, Gower-Rousseau C, Macry J, Merlin F, Chamaillard M, Jannot AS, Thomas G, Hugot JP, EPWG-IBD Group, EPIMAD Group, GETAID Group: CARD15/NOD2 mutational analysis and genotype-phenotype correlation in 612 patients with inflammatory bowel disease. Am J Hum Genet 2002, 70:845-857.

25. Stockton JC, Howson JM, Awomoyi AA, McAdam KP, Blackwell JM, Newport MJ: Polymorphism in NOD2, Crohn's disease, and susceptibility to pulmonary tuberculosis. FEMS Immunol Med Microbiol 2004, 41:157-160.

\section{Pre-publication history}

The pre-publication history for this paper can be accessed here: http://www.biomedcentral.com/1471-2334/12/91/prepub

doi:10.1186/1471-2334-12-91

Cite this article as: Zhao et al: A novel single nucleotide polymorphism within the NOD2 gene is associated with pulmonary tuberculosis in the Chinese Han, Uygur and Kazak populations. BMC Infectious Diseases 2012 12:91. 